\title{
Imaging of Copper, Zinc, and Other Elements in Thin Section of Human Brain Samples (Hippocampus) by Laser Ablation Inductively Coupled Plasma Mass Spectrometry
}

\author{
J. S. Becker, ${ }^{\star \dagger}$ M. V. Zoriy, ${ }^{\dagger}$ C. Pickhardt, ${ }^{\dagger}$ N. Palomero-Gallagher, ${ }^{\ddagger}$ and K. Zilles ${ }^{\ddagger}$ \\ Central Division of Analytical Chemistry and Institute of Medicine, Research Centre Juelich, D-52425 Juelich, Germany
}

Laser ablation inductively coupled plasma mass spectrometry (LA-ICPMS) was used to produce images of element distribution in $20-\mu \mathrm{m}$ thin sections of human brain tissue. The sample surface was scanned (raster area $\sim 80 \mathrm{~mm}^{2}$ ) with a focused laser beam (wavelength $213 \mathrm{~nm}$, diameter of laser crater $50 \mu \mathrm{m}$, and laser power density $3 \times 10^{9} \mathrm{~W} \mathrm{~cm}^{-2}$ ) in a cooled laser ablation chamber developed for these measurements. The laser ablation system was coupled to a double-focusing sector field ICPMS. Ion intensities of ${ }^{31} \mathrm{P}^{+},{ }^{32} \mathrm{~S}^{+},{ }^{56} \mathrm{Fe}^{+},{ }^{63} \mathrm{Cu}^{+}$, ${ }^{64} \mathrm{Zn}^{+},{ }^{232} \mathrm{Th}^{+}$, and ${ }^{238} \mathrm{U}^{+}$were measured within the area of interest of the human brain tissue (hippocampus) by LA-ICPMS. The quantitative determination of copper, zinc, uranium, and thorium distribution in thin slices of the human hippocampus was performed using matrixmatched laboratory standards. In addition, a new arrangement in solution-based calibration using a micronebulizer, which was inserted directly into the laser ablation chamber, was applied for validation of synthetic laboratory standard. The mass spectrometric analysis yielded an inhomogeneous distribution (layered structure) for $\mathrm{P}, \mathrm{S}, \mathrm{Cu}$, and $\mathrm{Zn}$ in thin brain sections of the hippocampus. In contrast, $T h$ and $U$ are more homogeneously distributed at a low-concentration level with detection limits in the low-nanogram per gram range. The unique analytical capability and the limits of LA-ICPMS will be demonstrated for the imaging of element distribution in thin cross sections of brain tissue from the hippocampus. LA-ICPMS provides new information on the spatial element distribution of the layered structure in thin sections of brain tissues from the hippocampus.

The analysis of element distribution (imaging) in thin section of biological tissues is a challenging task in analytical chemistry and is of interest in different areas of biological research. The deficit of essential elements in human tissue (e.g., $\mathrm{Fe}, \mathrm{Cu}, \mathrm{Se}$, $\mathrm{Zn}, \mathrm{Mn}, \mathrm{Mo}, \mathrm{Co}, \mathrm{Ni})$ results in deficiency diseases, but metals

\footnotetext{
* To whom correspondence should be addressed. Telephone: 00492461 612698. Fax: 00492461 612560. E-mail: s.becker@fz-juelich.de.

$\dagger$ Central Division of Analytical Chemistry.

¥ Institute of Medicine.
}

can also catalyze cytotoxic reactions or are toxic at high concentrations.

It is well known that metals (e.g., $\mathrm{Cu}, \mathrm{Fe}, \mathrm{Zn}, \mathrm{Se}, \mathrm{Mn}, \mathrm{Ca}, \mathrm{Mg}$, and others) and nonmetals, such as P and S, are inhomogeneously distributed in biological or medical tissues. Investigating element distribution in thin tissue slices requires sensitive analytical techniques and powerful equipment. Most analytical techniques for the visualization of inhomogeneous distributions of elements in tissues (e.g., histological or histochemical staining techniques) possess poor detection limits-that means, no element can be detected at trace and ultratrace concentrations. Furthermore, it is difficult to obtain reliable quantitative analytical results. In addition, these element-specific staining methods only allow one element to be mapped in the same section. Other analytical techniques, such as scanning electron microscopy with energy disperse X-ray analysis, ${ }^{1}$ microproton-induced X-ray emission, ${ }^{2}$ and autoradiography, ${ }^{3}$ are not sensitive enough for trace element determination due to low detection power, and there are also difficulties in quantifying analytical data on medical tissues. Furthermore, the application of matrix-assisted laser desorption/ ionization mass spectrometry was described as an additional mapping method especially for organic compounds in tissues and imaging of peptides and proteins by Caprioli et al. ${ }^{4,5}$ and Luxembourg et al. ${ }^{6}$

For the determination of element distribution on surfaces of biological samples, secondary ion mass spectrometry (SIMS) ${ }^{7-9}$ or laser ablation inductively coupled plasma mass spectrometry (LA-ICPMS) are sensitive surface analytical techniques. ${ }^{10-12}$ SIMS

(1) Mizuriha, V.; Hasegawa, H.; Notoya, M. Acta Histochem. Cytochem. 1997 $30,3125-35$.

(2) Mesjasz-Przybylowicz, J.; Przybylowicz, W. J. Nucl. Instrum. Methods B 2002, 189, 470-81.

(3) Takeda, A.; Tamano, H.; Enomoto, S.; Oku, N. Cancer Res. 2001, 61, 5065.

(4) Todd, P. J.; Schaaf, T. G.; Chaurand, P.; Caprioli, R. M. J. Mass Spectrom. 2001, 36, 355-369.

(5) Chaurand, P.; Caprioli, R. M. Electrophoresis 2002, 23, 3125-35.

(6) Luxembourg, S. L.; Mize, T. H.; McDonnell, L. A.; Heeren, R. M. A. Anal. Chem. 2004, 76, 5339-44.

(7) Morrison, G. H.; Gay, I.; Cahndra, S. Scanning Microsc. Suppl. 1994, 8, 359

(8) Chandra, S. Appl. Surf. Sci. 2003, 203-204, 679-83.

(9) Touboul, D.; Halgand, F.; Brunelle, A.; Kersting, R.; Tallarek, E.; Hagenhoff, B.; Laprevote, O. Anal. Chem. 2004, 76, 1550-9.

(10) Feldmann, J.; Kindness, A.; Ek, P. J. Anal. At. Spectrom. 2002, 17, 813-8.

(11) Ghazi, A. M.; Wataha, J. C.; O’Dell, N. L.; Singh, B. B.; Simmons, R.; Shuttleworth, S. J. Anal. At. Spectrom. 2002, 17, 1295-9. 


\section{Table 1. Optimized Experimental Parameters of LA-ICPMS}

ICPMS (Element, Thermo Electron, Bremen) rf power, $\mathrm{W}$ auxiliary gas flow rate, $\mathrm{L} \mathrm{min}^{-1} \quad 18$ carrier gas flow rate, $\mathrm{L} \mathrm{min}^{-1} \quad 1.2$ mass resolution $(m / \Delta m) \quad 4400$ number of runs (pass) 150 (1) analysis time per line $(5 \mathrm{~mm})$, $\mathrm{min}$

$\begin{array}{lll}1200 & \text { laser ablation system } & \text { Ablascope } \\ 18 & \text { wavelength, } \mathrm{nm} & 213 \\ 1 & \text { laser power density, } \mathrm{W} \mathrm{cm}^{-2} & 3 \times 10^{9} \\ 1.2 & \text { laser energy per pulse, } \mathrm{mJ} & 6 \\ 4400 & \text { repetition frequency, } \mathrm{Hz} & 20 \\ 150(1) & \text { spot diameter, } \mu \mathrm{m} & 50 \\ 12 & \text { temperature of tissue, }{ }^{\circ} \mathrm{C} & -10\end{array}$

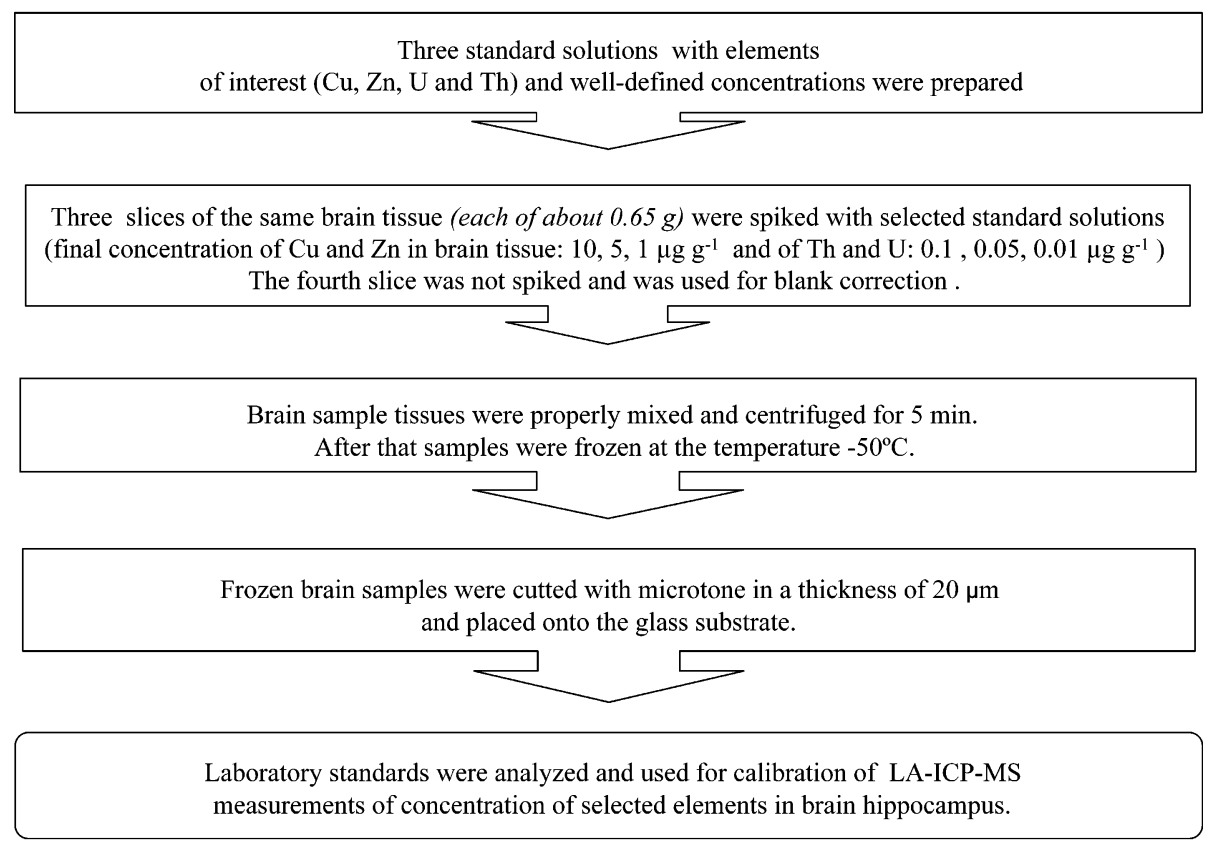

Figure 1. Preparation of synthetic matrix-matched laboratory standards.

can directly produce ion images of element distribution ${ }^{7}$ and of organic compounds ${ }^{4}$ in tissue with a lateral resolution in the lowmicrometer and submicrometer range. The highest lateral resolution for tissue analysis is possible in SIMS using a liquid metal primary ion source, e.g., ${ }^{69} \mathrm{Ga}^{+}$or gold cluster beams. ${ }^{9}$ For example, the lateral isotope distribution in a cross section of part of a plant in the framework of tracer studies using enriched stable isotopes was measured by means of SIMS (using the ion microscope mode) with a gallium primary ion source, whereby the lateral resolution was $\sim 100 \mathrm{~nm} . .^{13}$ A disadvantage of SIMS is that, due to inherent matrix effects up to 6 orders of magnitude, the quantification of analytical data is problematical. In contrast, in LA-ICPMS, significantly lower matrix effects were observed. Therefore, the quantification procedures of analytical data are less problematic. LA-ICPMS enables the semiquantitative analysis in short time of unknown samples. A further main advantage of LA-ICPMS in comparison to SIMS is that this analytical technique provides easy-to-quantify analytical data of multielement analysis (determination of major, minor, trace, and ultratrace elements in bulk analysis). ${ }^{14}$ LA-ICPMS ${ }^{15-17}$ uses a focused laser beam for

(12) Kindness, A.; Sekaran, N.; Feldmann, J. Clin. Chem. 2003, 49, 1916-23. (13) Becker, J. S.; Dietze, H. J. Int. J. Mass Spectrom. 2000, 197, 1-35.

(14) Becker, J. S. Spectrochim. Acta 2002, B 57, 1805-20.

(15) Durrant, S. F. J. Anal. At. Spectrosc. 1999, 14, 1385.

(16) Becker, J. S.; Pickhardt, C.; Dietze, H.-J. Int. J. Mass Spectrom. 2000, 203, 283-97.

(17) Becker, J. S.; Dietze, H.-J. Int. J. Mass Spectrom. 2003, 228, 127-50. evaporation of solid sample where the ablated material is transported into the inductively coupled plasma of an ICPMS using mostly Ar as carrier gas. This multielement analytical technique is applied especially for determining the element composition of trace elements and isotope ratios in solid samples, e.g., geological samples ${ }^{18,19}$ or high-purity materials. ${ }^{17}$ At present, the application of LA-ICPMS in biological research and in medicine focuses on individual tasks, e.g., the determination of element distribution in tree barks, ${ }^{20}$ in green leaves, ${ }^{21}$ in tissues of fish, ${ }^{22}$ or for element mapping in liver sections of sheep. ${ }^{12}$ Furthermore, LA-ICPMS was used in our laboratory for extreme ultratrace and isotope analysis of actinides (especially of plutonium) in moss samples ${ }^{23}$ and for the determination (including isotope ratio measurements) of longlived radionuclides in body fluids (urine) ${ }^{24}$ The reason for the relatively limited application of LA-ICPMS in biological and

(18) Jochum, K. P.; Stoll, B.; Herwig, K.; Amini, M.; Abouchami, W.; Hofmann A. W. Int. J. Mass Spectrom. 2005, 242, 281-289.

(19) Pickhardt, C.; Brenner, I. B.; Becker, J. S.; Dietze, H. J. Fresenius' J. Anal. Chem. 2000, 368, 79-87.

(20) Hoffmann, E.; Lüdke, C.; Stephanowitz, H. Fresenius' J. Anal. Chem. 1996, 355, 900-3.

(21) Hoffmann, E.; Lüdke, C.; Scole, J.; Stephanowitz, H.; Ullrich, E.; Colditz, D. Fresenius' J. Anal. Chem. 2000, 367, 579-85.

(22) Ek, P. European Winter Conference on Plasma Spectrochemistry, 10-15 January 1999; Poster E 28.

(23) Boulyga, S. F.; Desideri, D.; Meli, M. A.; Testa, C.; Becker, J. S. Int. J. Mass Spectrom. 2003, 226, 329-39.

(24) Becker, J. S.; Burow, M.; Boulyga, S. F.; Pickhardt, C.; Hille, R.; Ostapczuk, P. At. Spectrosc. 2004, 25, 197-202. 


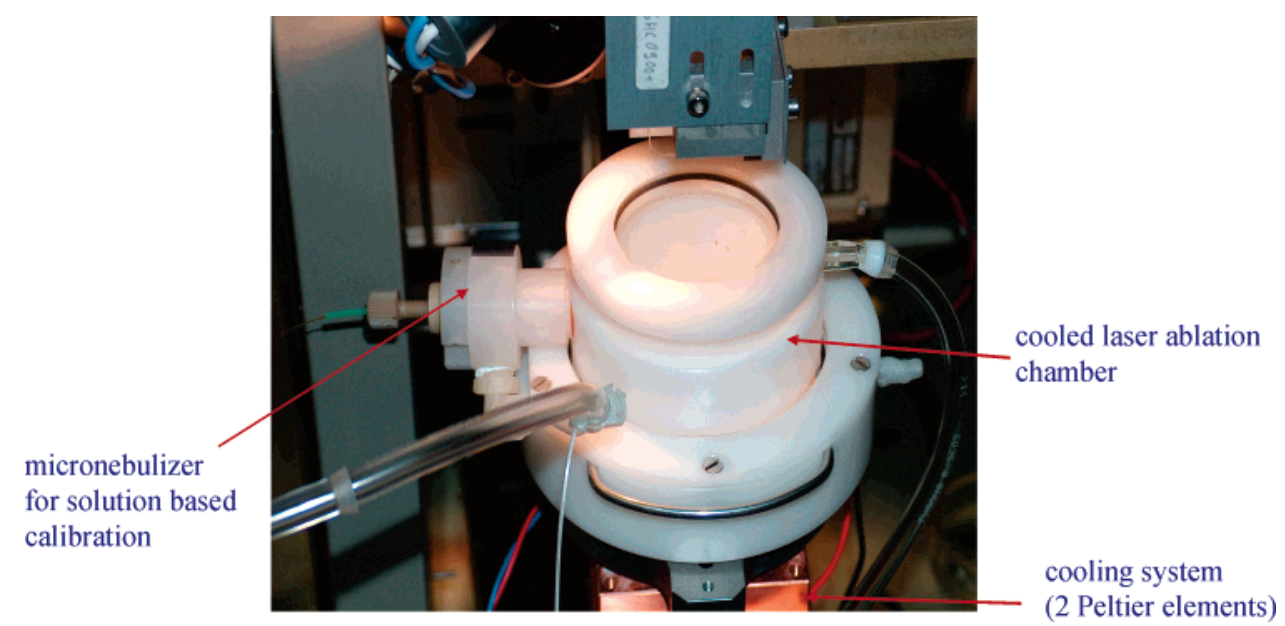

Figure 2. Experimental setup for on-line solution-based calibration in LA-ICPMS using a micronebulizer inserted directly in the cooled laser ablation chamber.

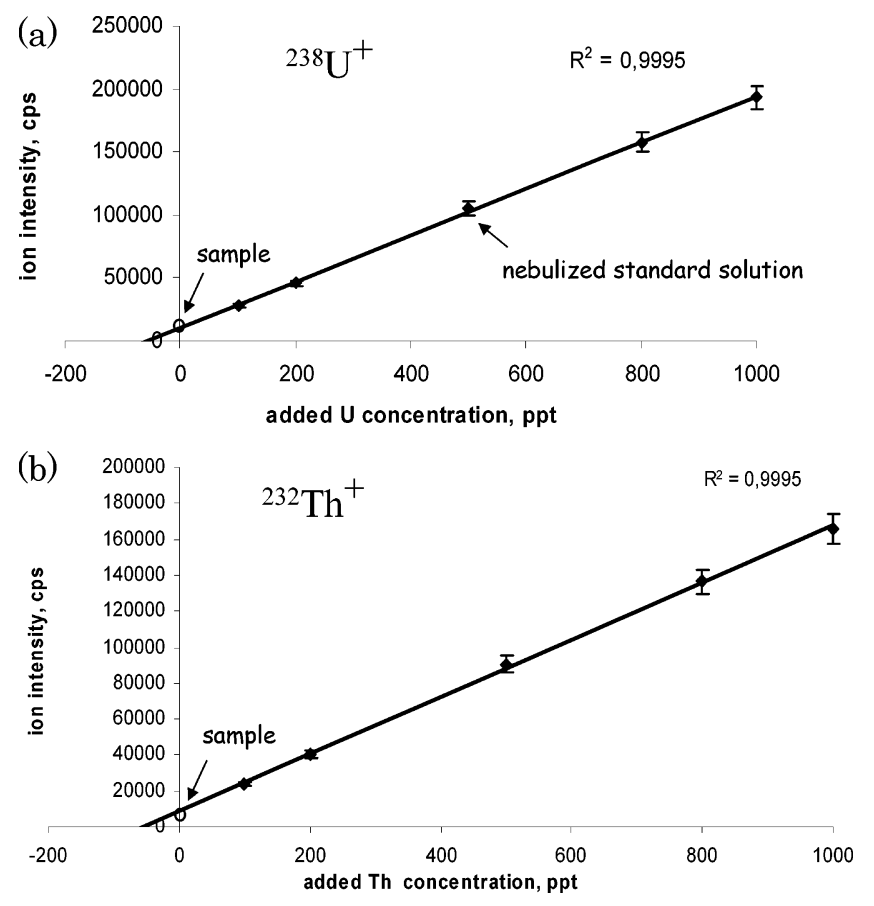

Figure 3. Calibration curves for uranium (a) and thorium (b) determination in brain samples via a standard addition mode using micronebulization in LA-ICPMS.

medical research can be explained by difficulties in the laser ablation of biological matrixes, in the lack of suitable analytical procedures for quantitatively determining element concentration, and in the relatively high price of modern and powerful laser ablation systems with a good lateral resolution power. At the small laser focus (low-micrometer range)-required often for the determination of element distribution in tissues-older commercial laser ablation systems possess a low laser power density, mostly less than $10^{8} \mathrm{~W} / \mathrm{cm}^{2}$, and therefore not enough material is ablated for a sensitive element analysis. Furthermore, to avoid fractionation effects in laser microlocal analysis at lateral resolution in the low-micrometer range, a laser power density higher than $10^{9} \mathrm{~W} / \mathrm{cm}^{2}$ should be applied. ${ }^{19}$

Considering ICPMS, which is the most widely applied trace and ultratrace analytical method today, the main features are the multielement capability and the possibility of a fast and reliable

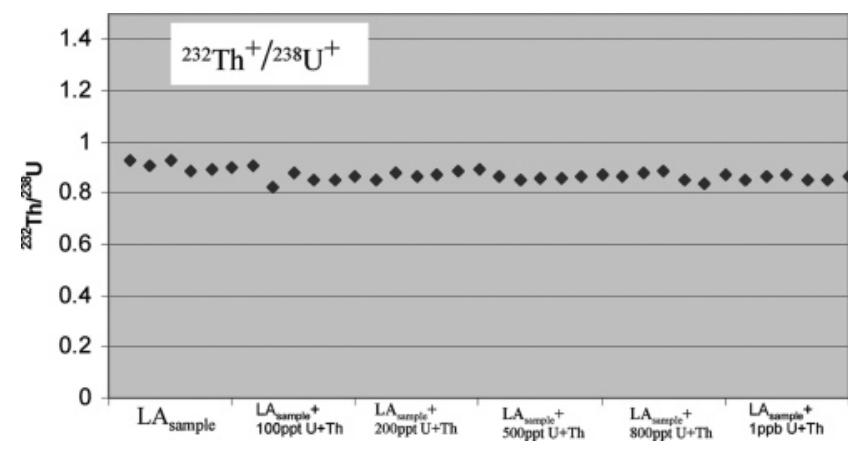

Figure 4. ${ }^{232} \mathrm{Th}^{+} / 238 \mathrm{U}^{+}$intensity ratio measured via standard addition mode using micronebulization in LA-ICP-SFMS.

element and isotope analysis down to the ultratrace level on any sample material, and consequently, very large application fields in biology and medicine have been observed. The quantification of measured ion intensities in ICPMS in comparison to solid-state analytical techniques (LA-ICPMS and SIMS) is simple using defined matrix-matched standard solutions by an external calibration, standard addition method, or the isotope dilution technique. In addition, ICPMS in combination with hyphenated techniques enables the analysis of species of trace elements; e.g., Richarz and Brätter ${ }^{25}$ determined metallothionine in brain samples of patients with Alzheimer's disease. The determination of $\mathrm{Cd}$ as a toxic metal and $\mathrm{Zn}$ as an essential metal in brain samples of patients with Alzheimer's disease by means of ICPMS was described by Panayi et al. ${ }^{26}$ Recently, Tarohda et al..$^{27}$ studied the regional distribution of selected essential elements $(\mathrm{Mn}, \mathrm{Fe}, \mathrm{Cu}$, $\mathrm{Zn}$ ) in different regions of rat brains during the developmental phase of the brain by ICPMS. Element distribution can be measured by ICPMS only if a local area of tissue were cut out in a well-defined manner and analyzed with respect to element composition, e.g., microwave-induced digestion. However, each analysis by ICPMS supplies only the average element concentration in the investigated region of tissue whereby the lateral resolution is determined by the preparation technique. The

(25) Richarz, A.-N.; Brätter, P. Anal. Bioanal. Chem. 2002, 372, 412.

(26) Panayi, A. E.; Spyrou, N. M.; Iversen, B. S.; White, M. A.; Part, P. J. Neurol. Sci. 2002, 195, 1-10.

(27) Tarohda, T.; Yamamoto, M.; Amamo, R. Anal. Bioanal. Chem. 2004, 380, $240-246$. 

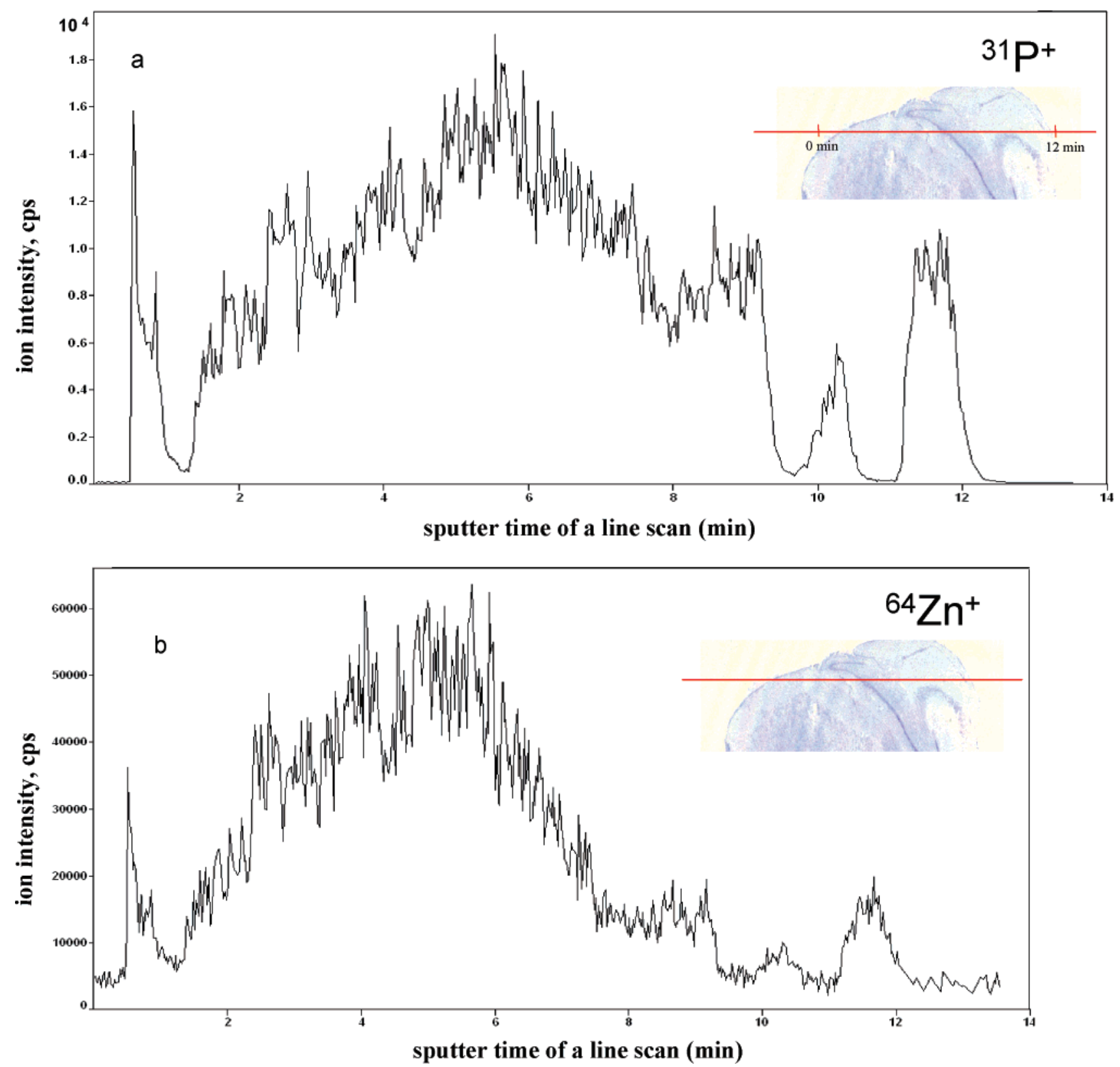

Figure 5. Measured ion intensity of (a) phosphorus and (b) zinc in a line scan in the cross section of brain samples (hippocampus) using LA-ICPMS. The red line in the inset histological section indicates the position from which phosphorus and zinc measurements were obtained.

drawback of these studies is the high experimental effort and the low lateral resolution of element distribution images, so that the development of a direct microlocal analytical LA-ICPMS method is advantageous.

Kindness et al. ${ }^{12}$ proposed an analytical technique using LA-ICPMS for the quantitative determination of two-dimensional element distribution (mapping) of $\mathrm{Cu}$ and $\mathrm{Zn}$ in sections of tissue (sheep liver). For the calibration of the analytical procedure, a homogeneous certified reference material (CRM LGC 7112, pig liver) was applied. The authors used LA-ICPMS with a commercial cryogenically cooled laser ablation chamber for the direct analysis of tissues, which was described for the first time by Feldmann et al. ${ }^{10}$

Recently, we developed a cooled laser ablation chamber (using two Peltier elements behind the target holder made of aluminum) for the LA-ICPMS analysis of thin brain sections. This experi- mental arrangement resulted in a significant improvement of stability of the ion currents, thus leading to a better precision and higher accuracy of analytical data as demonstrated for uranium isotope ratio measurements on the surface of a biological tissue in previous work. ${ }^{28}$ Furthermore, LA-ICPMS was developed as a microanalytical method in our laboratory for the determination of $\mathrm{P}, \mathrm{S}, \mathrm{Si}$, and metal concentrations ( $\mathrm{Al}, \mathrm{Zn}, \mathrm{Cu}, \mathrm{Fe}$ ) in well-separated protein spots after two-dimensional gel electrophoresis in brain samples of patients with Alzheimer's disease and in control brains. ${ }^{29}$ Because there is a lack of suitable matrixmatched standard reference materials in LA-ICPMS, different calibration strategies were developed: the preparation of synthetic

(28) Zoriy, M.; Kayser, M.; Pickhardt, C.; Becker, J. S. Int. J. Mass Spectrom. 2005, 242, 297-302.

(29) Becker, J. Su.; Zoriy, M.; Becker, J. S.; Pickhardt, C.; Przybylsky, M. J. Anal. At. Spectrosc. 2004, 19, 149-52. 

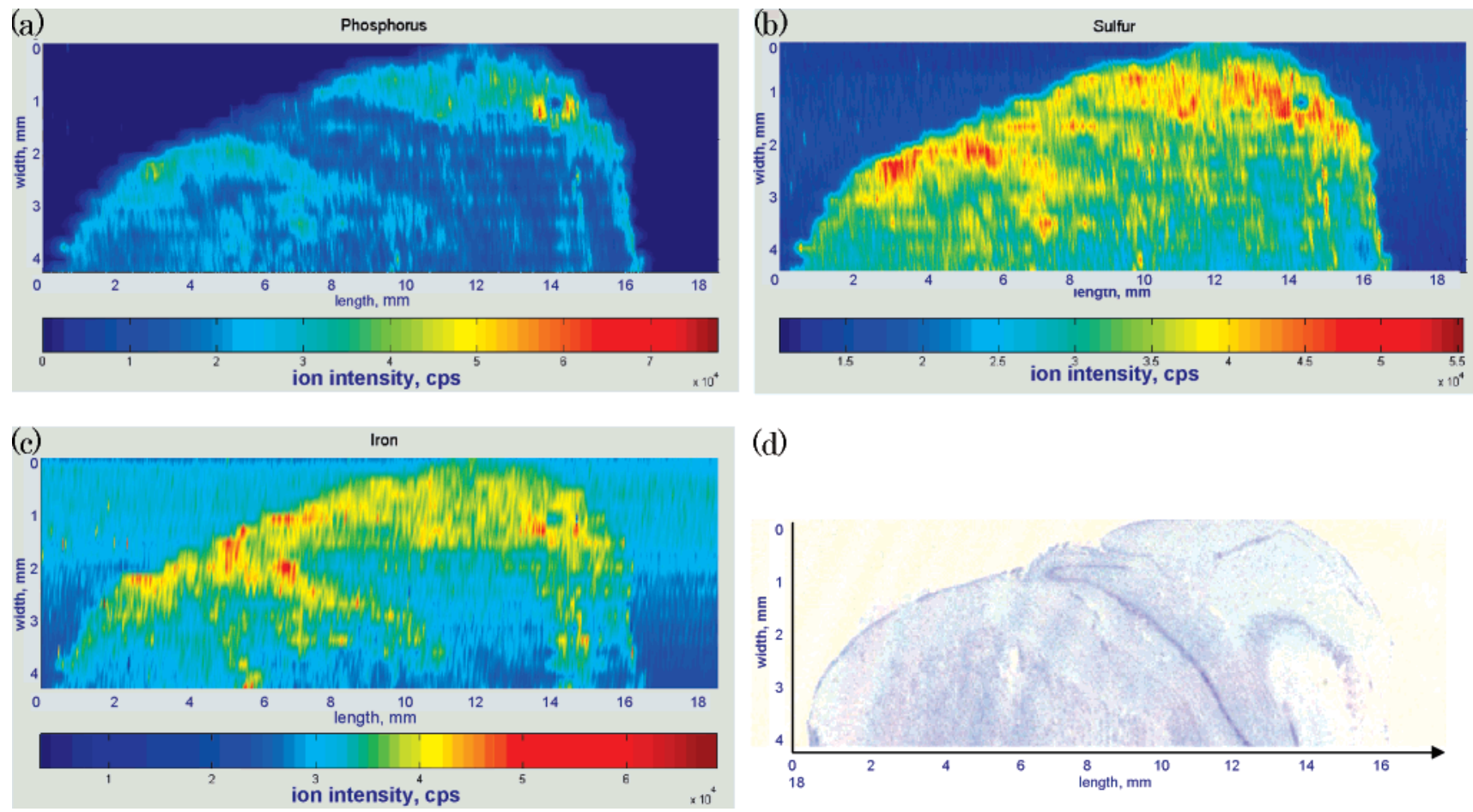

(d)

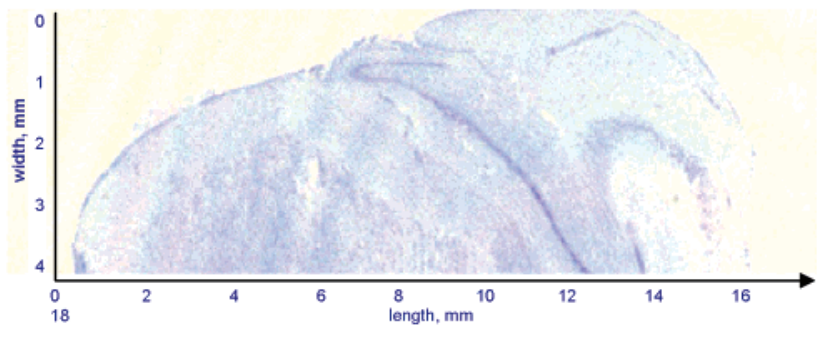

Figure 6. Distribution of (a) phosphorus, (b) sulfur, and (c) iron measured by LA-ICPMS in the human hippocampus. (d) Histologically processed brain tissue in which cell bodies were stained in order to demonstrate the layered structure of the analyzed region.

laboratory standards or solution-based calibration, ${ }^{14}$ which was used for the determination of phosphorus in protein spots in gels separated by two-dimensional gel electrophoresis. ${ }^{30}$ The spatial resolution of LA-ICPMS in the micrometer range is sufficient to distinguish between several layered structures in human brain tissue from the hippocampus, as described by Zilles et al. ${ }^{31}$

The aim of this work is the development of a new microanalytical technique using LA-ICPMS for the simultaneous and quantitative determination of element distribution in thin sections of human brain tissues. The results on selected sections of brain tissue measured by LA-ICPMS will provide important information on the lateral and depth element distribution of essential and toxic elements in human brain samples (e.g., the determination of toxic concentrations of copper and/or iron ions, which play an important role in degenerative processes).

\section{EXPERIMENTAL SECTION}

LA-ICPMS Instrumentation. A double-focusing sector field ICPMS (ICPMS, ELEMENT, Thermo Electron Corp., Bremen, Germany) coupled to a powerful laser ablation system Ablascop (Bioptic, Berlin, Germany) was used for imaging of $\mathrm{Cu}, \mathrm{Zn}$, and other elements in thin brain tissue (hippocampus) sections (thickness $20 \mu \mathrm{m}$ ). The experimental arrangement of LA-ICPMS with cooled laser ablation chamber is shown in ref. 28. The laser ablation of thin brain sections was performed with a frequency quintupled Nd:YAG laser (wavelength $213 \mathrm{~nm}$, repetition frequency $20 \mathrm{~Hz}$, spot diameter $50 \mu \mathrm{m}$; laser power density $3 \times$ $10^{9} \mathrm{~W} \mathrm{~cm}^{-2}$ ) in the cooled laser ablation chamber. The ablated

(30) Becker, J. S.; Boulyga, S. F.; Becker, J. Su.; Pickhardt, C.; Damoc, E. Przybylski, M. Int. J. Mass Spectrom. 2003, 228, 985-97.

(31) Zilles, K.; Palomero-Gallagher, N.; Grefkes, C.; Scheperjans, F.; Boy, C.; Amunts, K.; Schleicher, A. Eur. Neuropsychopharm. 2002, 12, 587-99. material was transported by argon as a carrier gas into the ICP. The ions formed in the ICP were extracted into the sector field mass spectrometer and separated according to their mass-tocharge ratios. To separate interfering molecular ions from the atomic ions $\mathrm{S}^{+}, \mathrm{P}^{+}, \mathrm{Cu}^{+}, \mathrm{Zn}^{+}$, and $\mathrm{Fe}^{+}$, all LA-ICPMS measurements were performed at medium mass resolution $m / \Delta m$ of 4400 . The ICP torch was shielded with a grounded platinum electrode (GuardElectrode, Thermo Electron Corp.). For calibration, a single gas flow solution-based procedure was applied using an ultrasonic nebulizer (USN, CETAC Technologies Inc., Omaha, NE) described elsewhere. ${ }^{30}$ Using this arrangement, simultaneous optimization of the nebulizer gas flow rate for the USN and the carrier gas flow rate for the transport of laser-ablated material into ICP is possible. The experimental parameters of LA-ICPMS were optimized with respect to the maximum ion intensity of ${ }^{63} \mathrm{Cu}^{+}$ using a $1 \mu \mathrm{g} \mathrm{L} \mathrm{L}^{-1}$ copper solution introduced by the USN, which was coupled on-line to the cooled laser ablation chamber. Maximum ion intensity was observed at a carrier gas flow rate of $1.2 \mathrm{~L} \mathrm{~min}^{-1}$ for the transport of ablated material to the ICPMS whereby an optimum mixing of nebulized standard solutions and laser-ablated solid sample directly in the ablation chamber was observed. Thin brain tissue sections were investigated with respect to the element distribution of $\mathrm{P}, \mathrm{S}, \mathrm{Zn}, \mathrm{Cu}, \mathrm{U}$, and Th. The background intensity of the analytes of interest was determined directly in a "blank" brain tissue (preparation of homogeneous synthetic laboratory standard is described below) by LA-ICPMS. The optimized experimental parameters for LA-ICPMS measurements of thin brain tissues are summarized in Table 1 .

Samples and Sample Preparation. Human hippocampi from brains with no record of neurological or psychiatric diseases were obtained at autopsy, frozen in isopentane, and stored in airtight bags at $-70{ }^{\circ} \mathrm{C}$. All subjects had given written consent before 

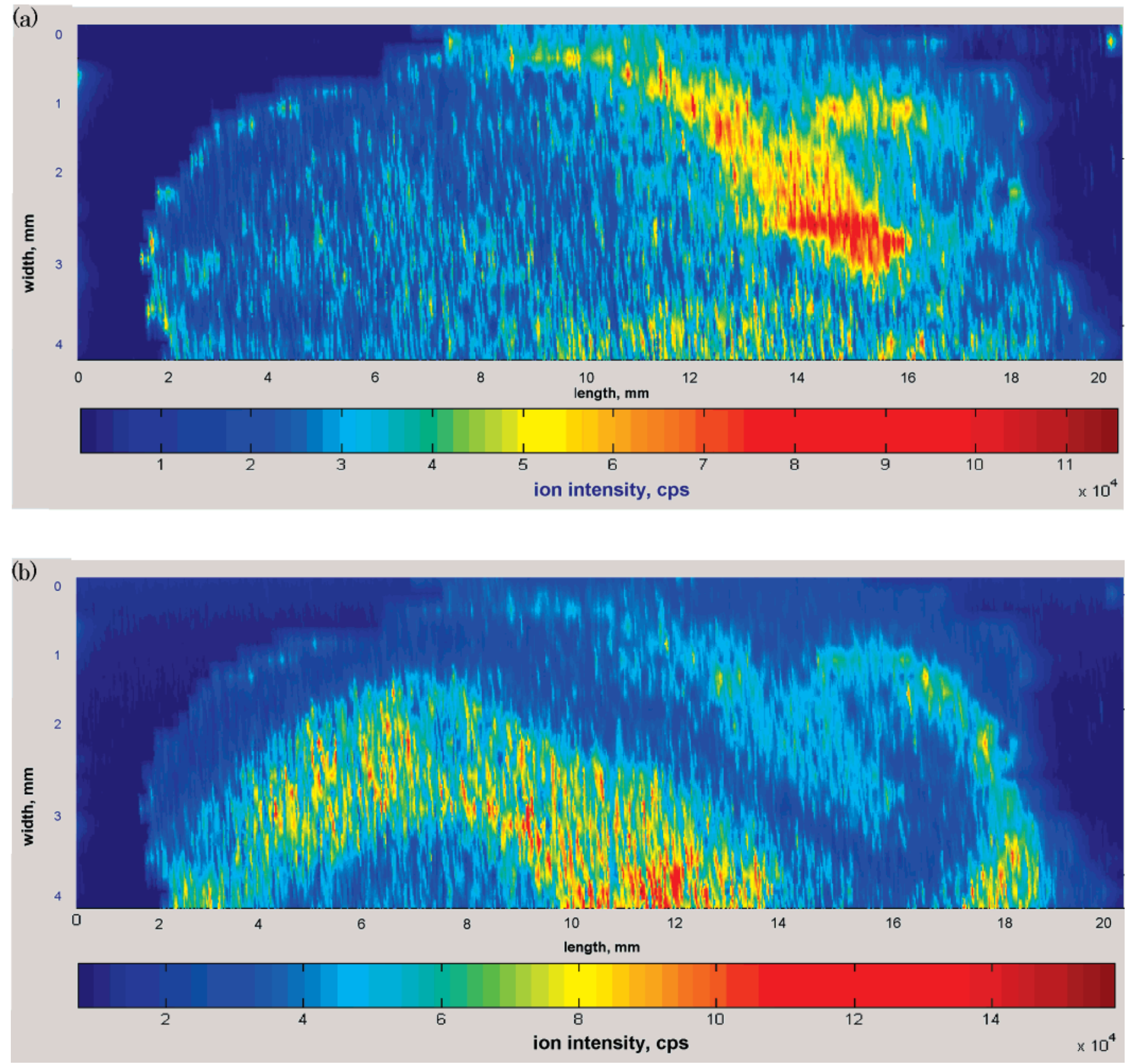

Figure 7. Element distribution (a) of zinc and (b) copper measured by LA-ICPMS in human hippocampus. Measured ion intensities are shown.

death or had been included in the body donor program of the Department of Anatomy, University of Düsseldorf, Germany. Serial $20-\mu \mathrm{m}$ sections were cut in a cryostat (Leica, CM3050S) at $-20{ }^{\circ} \mathrm{C}$ and thaw-mounted on glass slides. Neighboring sections were processed for the visualization of cell bodies by means of a cresyl violet staining.

Calibration Procedure. Matrix-matched laboratory standards with well-defined element concentrations were prepared for the calibration of analytical data. The procedure of standard preparation of matrix-matched synthetic laboratory standards is summarized in Figure 1. Three laboratory synthetic standard solutions containing the elements of interest $(\mathrm{Cu}, \mathrm{Zn}, \mathrm{U}, \mathrm{Th})$ in defined concentrations were prepared. Three slices of the same brain tissue (each $\sim 0.65 \mathrm{~g}$ ) were spiked with selected standard solutions. The final concentrations in brain tissue are 10,5 , and $1 \mu \mathrm{g} \mathrm{g}^{-1} \mathrm{Cu}$ and $\mathrm{Zn}$ and $0.1,0.05$, and $0.01 \mu \mathrm{g} \mathrm{g}^{-1} \mathrm{Th}$ and U. The fourth slice was not spiked and was used for blank correction. All tissue brain samples were carefully homogenized and centrifuged for $5 \mathrm{~min}$. After that, samples were frozen at a temperature of $-50{ }^{\circ} \mathrm{C}$. Frozen matrix-matched synthetic laboratory standards of human brain tissues from the hippocampus were cut into sections of $20 \mu \mathrm{m}$ thickness and placed onto the glass substrate. The matrix-matched synthetic laboratory standards were used in LA-ICPMS to produce calibration curves for quantification purposes.

New Strategy of Solution-Based Calibration in LA-ICPMS. For validation of analytical data obtained using calibration procedure with matrix-matched synthetic laboratory standards, a new strategy of solution-based calibration was introduced using an inserted micronebulizer in the cooled laser ablation chamber. The experimental arrangement of laser ablation chamber with micronebulizer is shown in Figure 2. During the laser ablation of thin 

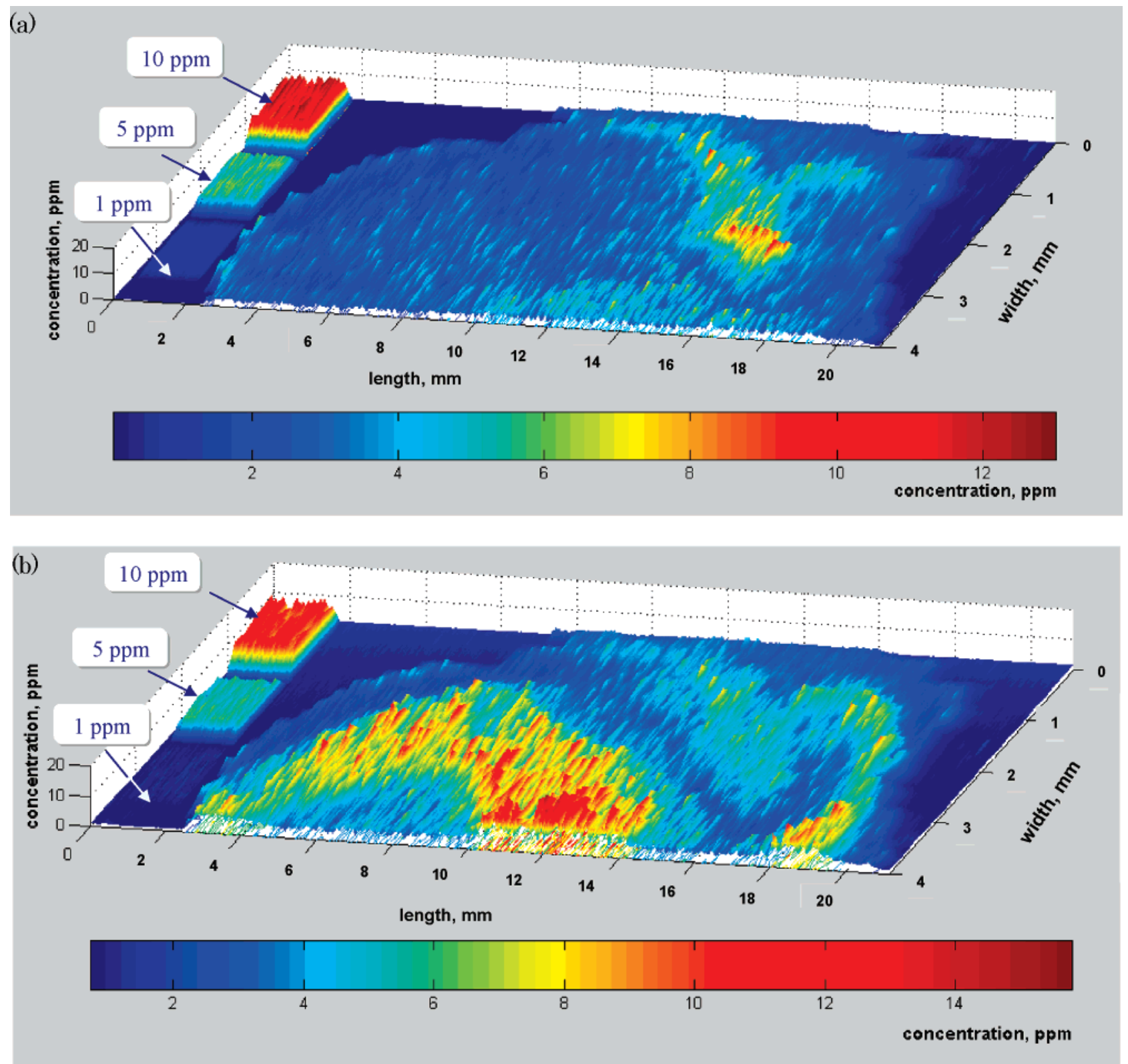

Figure 8. Concentration profile (a) of zinc and (b) copper measured by LA-ICPMS in human hippocampus. Calibration is performed via synthetic matrix-matched laboratory standards for 1,5 , and $10 \mathrm{ppm}$ analyte (see inset figures on left).

sections of biological tissue, defined standard solutions with increasing concentration were nebulized, whereby the calibration of the analytical method is performed by a standard addition mode. In this procedure, LA-ICPMS measurements were performed with a single line scan mode over the sample surface. The calibration curves for uranium and thorium determination in thin brain sections measured with LA-ICPMS are summarized in Figure 3. The regression coefficients for both calibration curves are better than 0.999 . Figure 4 demonstrates the ${ }^{232} \mathrm{Th}^{+} /{ }^{238} \mathrm{U}^{+}$intensity ratio by standard addition mode for different standard solutions using micronebulization in LA-ICPMS. For all measured concentrations of standard solution, the ${ }^{232} \mathrm{Th}^{+} /{ }^{238} \mathrm{U}^{+}$intensity ratio is nearly constant. To obtain quantitative data in a solution-based calibration, different element sensitivity in ICPMS and LA-ICPMS must be considered. For the correction of different element sensitivities in ICPMS and LA-ICPMS, the correction factor (concentration of internal standard element determined by solution-based calibration in LA-ICPMS/true concentration of internal standard element in the sample) was determined by use of either $U$ or Th. Both elements have been found to be homogeneous distributed within the human brain sample (see Figure 9) and therefore applied for internal standardization in the quantification procedure.

\section{RESULTS AND DISCUSSION}

Element Distribution on Thin Sections of Brain Tissue from the Hippocampus Measured by LA-ICPMS. In Figure $5 \mathrm{a}$ and $\mathrm{b}$, two ion intensity profiles of ${ }^{31} \mathrm{P}^{+}$and ${ }^{64} \mathrm{Zn}^{+}$in a section of brain tissue (hippocampus) are shown. The change in ion intensity demonstrates an inhomogeneous element distribution in the line scan measured (marked as red line). In both figures, the time scale correlates with a defined distance in the investigated brain sample scanned slowly by a focused laser beam. For further studies, the selected region of brain tissue was analyzed. To obtain two-dimensional imaging of element distribution, the region of 

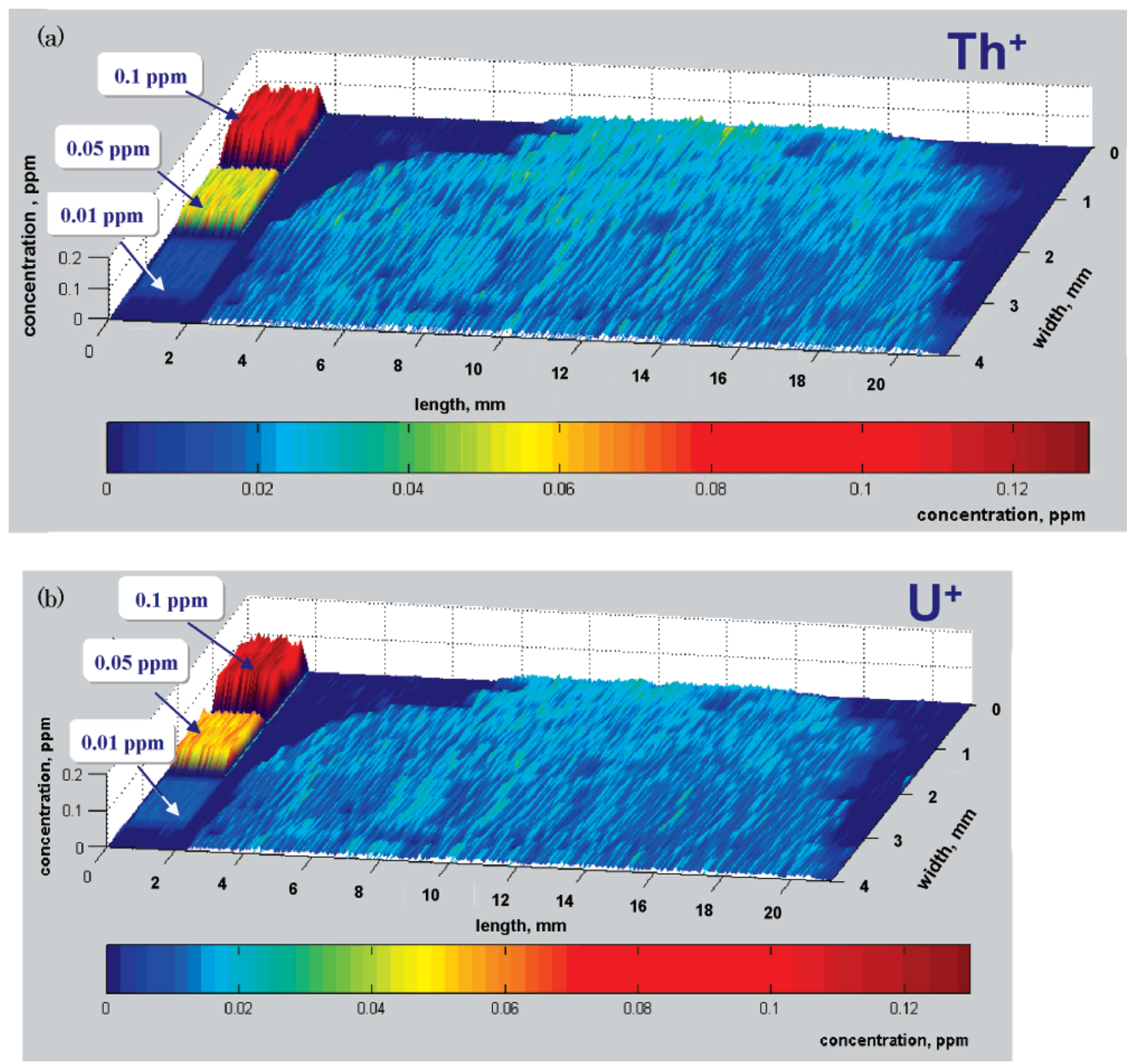

Figure 9. Concentration profile (a) of thorium and (b) uranium measured by LA-ICPMS in human hippocampus. Calibration is performed via synthetic matrix-matched laboratory standards for 10,50, and $100 \mathrm{ppb}$ analyte (see inset figures on left).

interest (see Figure 6d) was systematically screened (line by line). The spot size of laser craters was $50 \mu \mathrm{m}$. In Figure 6 , the ${ }^{31} \mathrm{P}^{+}$, ${ }^{32} \mathrm{~S}^{+}$, and ${ }^{56} \mathrm{Fe}^{+}$ion intensities for determination of phosphorus, sulfur, and iron element distribution in thin sections of hippocampal tissue by LA-ICPMS are represented. For these three essential elements, an inhomogeneous distribution was found. Due to the medium mass resolution applied in LA-ICPMS, the ion intensities of ${ }^{31} \mathrm{P}^{+},{ }^{32} \mathrm{~S}^{+}$, and ${ }^{56} \mathrm{Fe}^{+}$are relatively low. It was observed that the intensity distribution of the three elements shows a similar localization, with maximum ion intensities in the same hippocampal structures. Interesting however, is the fact, that maximum ion intensities of the three elements are present in the myelin dense layers (e.g., fimbria hippocampi). Panels a and b in Figure 7 demonstrate the two-dimensional representation of the distribution of zinc and copper in the analyzed hippocampus (see Figure 6d). As expected for zinc, which has been demonstrated in mossy fiber synapses by Danscher et al., ${ }^{32}$ the highest concentration of zinc was found in the hilus region and lucidum layer, i.e., the target of the mossy fibers. In contrast, copper (Figure $7 b$ ) reaches only relatively low ion intensity in this region, but much higher ion intensities (and, therefore, higher concentrations) were observed in the stratum lacunosum molecular layers of the cornu ammonis.

Quantification of Element Distribution on Thin Sections of Brain Tissue from the Hippocampus. Quantification Using Synthetic Matrix-Matched Laboratory Standards. The quantification of analytical data was performed by measurement of prepared synthetic matrix-matched laboratory standards with well-defined element concentrations. Calibration curves were measured and applied on the experimental results of brain sample studied by LA-ICPMS.

(32) Danscher, G.; Wang, Z.; Kim, Y. K.; Kim, S. J.; Sun, Y.; Jo, S. M. Neurosci. Lett. 2003, 342 (1-2), 81-4. 
Panels $\mathrm{a}$ and $\mathrm{b}$ in Figure 8 show the distribution patterns of zinc and copper in the human hippocampus. The layered distribution pattern of both elements is clearly visible. The three small inset figures (left) demonstrate the measured LA-ICPMS images of homogeneous synthetic matrix-matched laboratory standards with 1,5 , and $10 \mathrm{ppm}$ zinc (see Figure 8a). The zinc concentration (Figure 8a) in the investigated brain sample is mostly lower than $5 \mu \mathrm{g} \mathrm{g}^{-1}$. The maximal zinc concentration $\left(10 \mu \mathrm{g} \mathrm{g}^{-1}\right)$ is restricted to a small region of the hippocampus (in the hilus region and lucidum layer). Copper (Figure 8b) was found in higher overall concentrations (maximum $14 \mu \mathrm{g} \mathrm{g}^{-1}$ ) in the hippocampus. Furthermore, it was present not only in discrete concentrations in the hilus but also in higher concentrations in the pyramidal and lacunosum molecular layers of the cornu ammonis.

Of interest are the findings of element distribution for the radioactive elements thorium and uranium (Figure 9a and b). In contrast to the layered structure of the examined essential elements (Figures 6 and 8), thorium and uranium displayed a similar and relatively homogeneous profile in the cross section of the hippocampus as revealed by microlocal measurements using LA-ICPMS (see Figure 9). The measured uranium and thorium concentration was slightly higher than the detection limit. The detection limits of the microanalytical technique for Th and $\mathrm{U}$ determination in thin sections of brain tissues using LA-ICPMS were determined to be $10 \mathrm{ng} \mathrm{g}^{-1}$.

Application of On-Line Solution-Based Calibration Using Micronebulization in LA-ICPMS as a New Calibration Strategy. Finally, the accuracy of prepared matrix-matched laboratory standards was examined by a new calibration strategy using on-line solutionbased calibration with micronebulization of standard solution in LA-ICPMS. The experimental arrangement of laser ablation chamber with the inserted micronebulizer is shown in Figure 2. The applied calibration procedure using the standard addition mode with calibration solutions with defined concentration is described in the Experimental Section.

As an example, the uranium concentration in the prepared synthetic matrix-matched laboratory brain standard with uranium concentration of $100 \mathrm{ng} \mathrm{g}^{-1}$ was determined during laser ablation by standard addition mode. The uranium concentration in the prepared synthetic matrix-matched (brain) laboratory standard was determined by solution-based calibration LA-ICPMS to be $97.8 \pm 2.5 \mathrm{ng} \mathrm{g}^{-1}$. For the applied new microanalytical technique using a direct method of solution-based calibration in LA-ICPMS with cooled laser ablation chamber, the precision and accuracy was measured with $2-3 \%$.
Future studies will be focused on the development of on-line solution-based calibration for quantitative imaging of essential and toxic elements in brain samples using the isotope dilution technique and, furthermore, to introduce this technique into routine mode. Future systematic studies on thin sections of brain tissues from patients with different diseases in comparison to control brain tissues will focus on explaining fundamental processes such as the influence of essential and toxic elements on the development of diseases.

A significant improvement of lateral resolution (less than $1 \mu \mathrm{m}$ ) in LA-ICPMS for microlocal analysis in biological tissues combined with the possibility of quantitative element determination is necessary. At present we are developing new analytical LA-ICPMS techniques in our laboratory using the near-field effect for future interesting applications in life science and microelectronics. ${ }^{33}$

\section{CONCLUSION}

An analytical technique was developed for two-dimensional screening of $\mathrm{P}, \mathrm{S}, \mathrm{Fe}, \mathrm{Cu}, \mathrm{Zn}$, and Th and $\mathrm{U}$ in the cross section of the hippocampus using LA-ICPMS. Small sample size and sufficient sensitivity, as well as relatively short analysis time, prove that LA-ICPMS is a very powerful technique for multielemental distribution analysis on brain tissues. The quantification procedure developed using synthetic matrix-matched laboratory standards was successfully applied for determining the concentration of selected elements in thin cross sections of the hippocampus. In addition, the new calibration strategy was applied for validation of the analytical procedure using synthetic matrix-matched laboratory standards. The application of the developed analytical procedure for elemental screening of the hippocampus will help physicians to better understand the chemical basis of many brain diseases.

\section{ACKNOWLEDGMENT}

The authors gratefully acknowledge H.-J. Dietze (Jülich) for valuable discussion. The work was supported by the Deutsche Forschungsgemeinschaft, Bonn, Germany (SFB 575).

Received for review November 16, 2004. Accepted March 2, 2005.

\section{AC040184Q}

(33) Becker, J. S.; Kayser, M.; Gorbunov, A.; Pompe, W.; Rödel, G.; KrauseBuchholz, U.; Przybylski, M. Deutsche Patentanmeldung 10354787.8, 21.11.2003 